\title{
I!: \\ UTILIZAÇÃO DA AREIA MARINHA PARA PRODUÇÃO DE CONCRETO: ESTUDO DE VIABILIDADE
}

\section{USE OF SEA SAND FOR CONCRETE PRODUCTION: VIABILITY STUDY}

\author{
${ }^{1}$ Wandercleiton S. Cardoso* \\ ${ }^{2}$ Amandio Gonçalves de Oliveira Filho \\ ${ }^{3}$ Renée Lauret Cosme \\ ${ }^{4}$ Benigno Batista dos Santos \\ ${ }^{5}$ Diógenes Favalessa Lessa

\begin{abstract}
${ }^{1}$ Università degli Studi di Genova. E-mail: wandercleiton.cardoso@dicca.unige.it
${ }^{2}$ Universidade Federal do Espírito Santo. E-mail: amandiogeografo@gmail.com

${ }^{3}$ Universidade Federal do Espírito Santo. E-mail: lauret.cosme@gmail.com

${ }^{4}$ Instituto Capixaba de Pesquisa, Assistência Técnica e Extensão Rural. E-mail: benignobatista@gmail.com

${ }^{5}$ Universidade Federal do Espirito Santo. E-mail: lessa.di@gmail.com

*Autor de correspondência
\end{abstract}

Artigo submetido em 16/01/2021, aceito em 23/07/2021 e publicado em 06/08/2021.

Resumo: A indústria da construção civil tem destacado papel na sociedade brasileira devido a sua importância socioeconômica. Estudos conduzidos no Brasil e no exterior apontam que a areia marinha se apresenta como uma alternativa viável na construção civil. Nesta direção, esta pesquisa analisa uma amostra de agregado miúdo do litoral da Serra/ES, Brasil. Foram realizados ensaios de composição granulométrica, massa específica, teor de argilas em torrões, teor de materiais friáveis, teor de materiais pulverulentos, dimensão máxima característica, avaliação de impurezas orgânicas solúveis, teor de cloretos solúveis, teor de sais solúveis, teor de sulfatos solúveis, teor de materiais carbonosos e pH e resistência a compressão uniaxial. Os ensaios colorimétricos de avaliação de penetração de cloretos no concreto, imerso em água do mar durante 7 dias, não destacaram a presença de cloretos livres em nenhuma das amostras. Ensaios de carbonatação não revelaram processos de carbonatação nos três corpos de prova analisados. Os ensaios de resistência à compressão mostraram que o concreto moldado com areia marinha possui resultados próximos ao moldado com areia de rio.

Palavras-chave: Materiais de construção civil, concreto, agregado miúdo, areia marinha.

\begin{abstract}
The construction industry has an outstanding role in Brazilian society due to its socioeconomic importance. Studies conducted in Brazil and abroad indicate that marine sand is a viable alternative in civil construction. In this direction, this research analyzes a sample of fine aggregate from the coast of Serra/ES, Brazil. In this paper, tests of granulometric composition, specific mass, clay content in clods, content of friable materials, content of powdery materials, maximum characteristic dimension, evaluation of soluble organic impurities, soluble chloride content, soluble salt content, content of soluble sulphates, carbonaceous material content and $\mathrm{pH}$ and uniaxial compressive strength. The colorimetric tests to evaluate the penetration of chlorides in concrete, immersed in sea water for 7 days, did not highlight the presence of free chlorides in any of the samples. Carbonation tests did not reveal carbonation processes in the three specimens analyzed. Compressive strength tests showed that concrete cast with marine sand has results similar to those cast with river sand.
\end{abstract}

Keywords: Civil construction materials, concrete, fine aggregate, marine sand. 


\section{INTRODUÇÃO}

A exploração de dunas, planícies de rios e canais para extração de areias para utilização como agregados vem ocorrendo há muitos anos nas regiões metropolitanas brasileiras, ocasionando o exaurimento desses recursos minerais nas proximidades dos centros urbanos, bem como sérios problemas ambientais.

A exploração de areias marinhas para uso na construção civil é realizada em vários países ao redor do mundo, podendo se constituir em uma opção viável para países com área costeira extensa como o Brasil e com a maioria das cidades metropolitanas localizadas na zona costeira.

A utilização de areia marinha ainda é um desafio para a indústria da construção civil brasileira. Entretanto, esta realidade é diferente em diversos países do mundo que empregam esse agregado miúdo em vários processos construtivos (SILVA, 2018).

Por exemplo, este tipo de agregado é utilizado na fabricação de diferentes tipos de argamassas e concretos, inclusive do tipo estrutural além da reconstrução de perfis de praia e aterros. (CAVALCANTI e FREIRE, 2007, DHONDY et al., 2019).

O International Council for the Exploration of the Sea (ICES), uma organização intergovernamental que promove investigação marinha nos domínios do Atlântico Norte, aponta que no ano de 2008, 10 dos seus membros responderam pela produção de 44.573.464 $\mathrm{m}^{3}$ de areia marinha empregados na construção civil, com destaque para a Alemanha (19.262.151 $\left.\mathrm{m}^{3}\right)$ e Reino Unido $\left(9.457 .522 \mathrm{~m}^{2}\right)$, conforme pode ser observado na Tabela 1 (CAVALCANTI; FREIRE, 2007).
Embora não existam estudos quantitativos para o estado do Espírito Santo, as principais zonas de extração de areia estão localizadas nas proximidades do Rio Doce, dentro do próprio leito, ou nas planícies de inundação pretéritas, representando a produção em cavas.

Neste contexto, outro aspecto relevante, em relação à avaliação do uso da areia marinha, reside no custo do agregado miúdo que, embora seja um insumo barato na construção civil, é utilizado em grande escala, representando aproximadamente $28 \%$ do volume do concreto, o que é minimizado em função da proximidade da fonte produtora aos centros de consumo.

Considerando que, no Brasil, a maioria das regiões metropolitanas está localizada na zona costeira, e que as fontes de agregados miúdos nas proximidades já estão, em grande parte, exaurindo-se, além das dificuldades, justificáveis, impostas por restrições ambientais, o agregado miúdo marinho poderá ser um importante insumo para a indústria nacional.

No entanto, o país precisa avançar em pesquisas e regularização de áreas prováveis para esta atividade. Essa dificuldade é devida, em grande parte, à desconfiança da qualidade do agregado, embora já existam estudos publicados atestando a qualidade deste recurso, como os trabalhos de Augris e Cressard (1984), Cavalcanti e Freire (2007), Limeira, et al. (2010); Xiao et al. (2017), Ferreira (2019), Pranavan (2021) e Qing (2019).

Nesta direção, este trabalho objetiva apontar as características do emprego da areia marinha como agregado miúdo na produção de concreto, para tanto, assinala a possibilidade de estudo de caso de uma amostra de areia marinha do Espírito Santo, no litoral da cidade da Serra, Brasil. 
Tabela 1-: Produção de granulados marinho, em mega milhões de $\mathrm{m}^{3}$ e sua destinação dos principais países membros do International Concil for the Exploration of the Sea-ICES.

\begin{tabular}{|c|c|c|c|c|c|c|c|c|c|c|c|c|}
\hline \multicolumn{5}{|c|}{2007} & \multicolumn{4}{|c|}{2008} & \multicolumn{4}{|c|}{2009} \\
\hline 气ै & 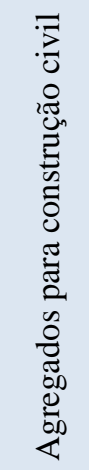 & 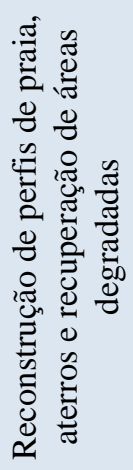 & 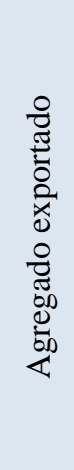 & 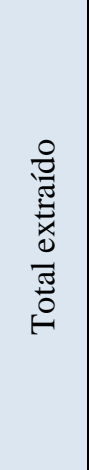 & 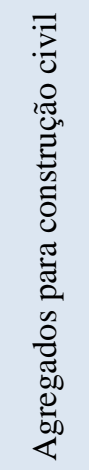 & 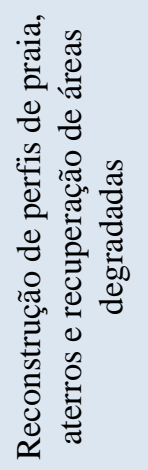 & 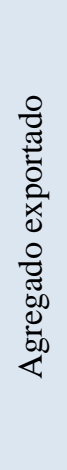 & 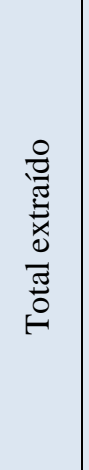 & 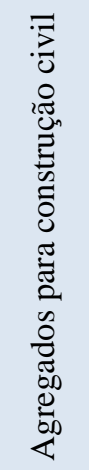 & 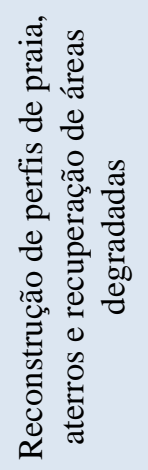 & 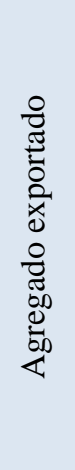 & 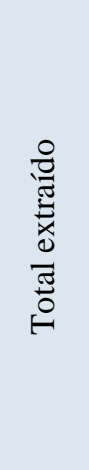 \\
\hline Bélgica & 1,5 & 0,5 & - & 2,0 & 1,8 & 0,5 & 0,3 & 2,6 & 1,7 & 0,3 & 0,3 & 2,4 \\
\hline Dinamarca & 6,5 & 2,1 & 0,4 & 9,0 & 6,5 & 2,1 & 0,4 & 9,0 & 3,1 & 4,1 & 0,5 & 7,7 \\
\hline França & 5,9 & - & - & 5,9 & 7,5 & 1,1 & - & 8,6 & 7,5 & - & - & 7,5 \\
\hline Alemanha & 0,1 & 1,3 & - & 1,4 & - & 2,1 & - & 2,1 & 19,3 & 1,3 & - & 20,6 \\
\hline Islândia & - & - & - & - & - & - & - & - & 0,4 & - & - & 0,4 \\
\hline Holanda & 1,9 & 26,4 & 2,9 & 31,2 & 1,7 & 24,7 & 3,3 & 29,6 & 2,5 & 117 & 2,4 & 121,9 \\
\hline Noruega & - & - & - & - & 0,1 & - & - & 0,1 & 0,1 & - & - & 0,1 \\
\hline Espanha & - & 0,1 & - & 0,1 & - & 0,8 & - & $\mathbf{0 , 8}$ & - & 0,6 & - & 0,6 \\
\hline Reino Unido & 12,7 & 1,3 & 4 & 18 & 11,7 & 1,3 & 3,7 & 16,7 & 9,5 & 2,7 & 3,4 & 15,6 \\
\hline EUA & 1,2 & 3,5 & - & 4,8 & 1 & 3,3 & - & 4,2 & 0,7 & 3,2 & - & 3,9 \\
\hline TOTAL & 29,8 & 35,1 & 7,2 & 72,3 & 30,1 & 35,8 & 7,6 & 73,5 & 44,6 & 129,1 & 6,7 & 180,4 \\
\hline
\end{tabular}

\section{REFERENCIAL TEÓRICO}

\subsection{Qualidade das areias marinhas}

Independente da origem do agregado, marinho ou continental, estes precisam ser adequados às normas da Associação Brasileira de Normas Técnicas $(A B N T)$ e na ausência ou deficiência destas às normas internacionais.

Os principais critérios de caracterização do agregado miúdo para justificar o seu emprego é o teor de carbonato de cálcio $\left(\mathrm{CaCO}_{3}\right)$ para areias que apresentam bioclastos e o teor em sais, além da granulometria, as propriedades físico-químicas. (TAMAR, 2017), (XU et al., 2021) e (YAMASHITA et al., 2020)

Do ponto de vista de qualificação do agregado miúdo, estes podem apresentar materiais nocivos à qualidade do concreto, os quais podem ser agrupados em três grandes grupos: impurezas de ação sobre a hidratação do cimento, substâncias que cobrem a superfície do agregado de forma a dificultar a aderência adequada do agregado à pasta de cimento e partículas friáveis (de forma geral de baixa resistência mecânica) que interferem na resistência do concreto (ZHOU et al., 2021), (ZHANG et al., 2010) e (HUANG, 2020).

Para este trabalho a discussão se pauta na possibilidade do emprego de areia marinha na fabricação de concreto. Segundo a NBR 7211 (ABNT, 2009), os agregados devem ser compostos por grãos de minerais duros, compactos, estáveis e limpos não contendo substâncias de natureza e em quantidade suficiente que 
possam afetar a hidratação e o endurecimento do cimento.

Segundo Ting et al. (2020), a matéria orgânica pode prejudicar a aderência do agregado à pasta além de interferir na pega e no endurecimento do concreto.

Ainda segundo Ting et al. (2020), a redução na resistência do concreto em função da matéria orgânica explica-se porque uma parte de húmus que é ácida neutraliza a água alcalina da argamassa e a parte restante envolve os grãos de areia formando uma película sobre eles impedindo, desta forma, uma perfeita aderência entre o cimento e as partículas de agregado.

Por estas razões, as argamassas e concretos preparados com areias que contenham uma proporção elevada de matéria orgânica têm baixa resistência.

Quanto à granulometria do agregado miúdo, um importante indicador é o módulo de finura obtido a partir dos limites de distribuição granulométrica do agregado, de acordo com a NBR 7211 (ABNT, 2009) este parâmetro é desejável estar situado entre 2,20 e 2,90, embora seja aceitável o seu emprego em outros limites (inferior varia de 1,55 a 2,20 e superior varia de 2,90 a 3,50 ).

Com relação às características da composição granulométrica, os estudos conduzidos por Cavalcanti e Freire (2007), em Fortaleza/CE, apontam que os resultados da areia marinha comparada com as areias de fonte continental mostraram-se satisfatórios.

A Tabela 2 apresenta os resultados dos autores. É importante notar que todos os parâmetros observados foram aceitáveis, inclusive o teor de matéria orgânica e materiais pulverulentos, que são fatores sensíveis.

As conchas representam o maior desafio ao trabalho com areias marinhas, entretanto, a norma francesa NF P18-540 (1997) estabelece o limite de $30 \%$ em teor de fragmentos de conchas para inviabilizar a areia.

Esse percentual pode ser reduzido através do peneiramento de $4 \mathrm{~mm}$ a $5 \mathrm{~mm}$, que possibilita a eliminação das conchas inteiras, consideradas as mais danosas.

Tabela 2: Comparação das características do agregado marinho e continental.

\begin{tabular}{|c|c|c|c|}
\hline & $\begin{array}{c}\text { Areias } \\
\text { Marinhas }\end{array}$ & $\begin{array}{c}\text { Areias } \\
\text { Continentais }\end{array}$ & Padrão \\
\hline $\begin{array}{l}\text { Dimensão máxima } \\
\text { característica (Dmáx) } \\
\text { (NBR NM 248) }\end{array}$ & $\begin{array}{l}1,2 \text { a } 9,5 \mathrm{~mm} \\
(4,8 \mathrm{~mm})\end{array}$ & $\begin{array}{c}1,2 \text { a } 6,3 \mathrm{~mm} \\
(4,8 \mathrm{~mm})\end{array}$ & - \\
\hline $\begin{array}{l}\text { Teor de argila em } \\
\text { torrões e materiais } \\
\text { friáveis (NBR 7218) }\end{array}$ & 0,01 a $0,86 \%$ & $\begin{array}{c}0,10 \text { a } 1,60 \% \\
(0,20 \%)\end{array}$ & Limite máximo: $1,5 \%$ \\
\hline $\begin{array}{c}\text { Avaliação de impurezas } \\
\text { orgânicas (NBR 7221) }\end{array}$ & $\begin{array}{l}\text { Todas as amostras com } \\
\text { resultado satisfatório }\end{array}$ & $\begin{array}{l}\text { Maioria das amostras com } \\
\text { resultado satisfatório }\end{array}$ & - \\
\hline $\begin{array}{l}\text { Teor de materiais } \\
\text { pulverulentos } \\
\text { (NBR 7220) }\end{array}$ & 0,40 a $2,94 \%$ & 0,60 a $3,00 \%$ & $\begin{array}{c}\text { Limites máximos: } \\
3 \% \text { para concretos } \\
\text { submetidos a desgaste } \\
\text { superficial e } \\
5 \% \text { para outros tipos }\end{array}$ \\
\hline Teor em Micas & $<1 \%$ & $<1 \%$ & Limite máximo: $5 \%$ \\
\hline $\begin{array}{c}\text { Reatividade Potencial } \\
\text { (NBR 9774) }\end{array}$ & Inócuas & Inócuas & - \\
\hline
\end{tabular}


A amostra de areia da pesquisa de Cavalcanti e Freire (2007) apresentou um teor em conchas de $25 \%$ no seu estado natural, sem o peneiramento, que possibilita o uso conforme a norma francesa. A Figura 1 apresenta os resultados de teor de carbonato de cálcio $\left(\mathrm{CaCO}_{3}\right)$ nas amostras de areias marinhas pesquisadas pelos autores.

Figura 1: Distribuição dos teores de $\mathrm{CaCO}_{3}$ nas amostras de areia marinha do litoral de Fortaleza/CE.

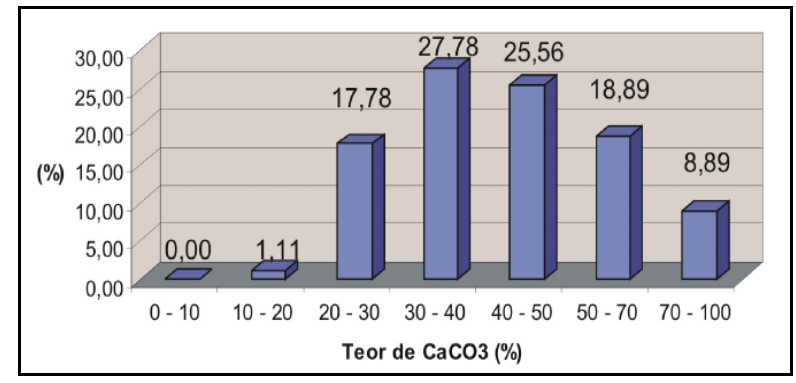

Fonte: Adaptado de Cavalcanti e Freire (2007).

Augris e Cressard (1984) apontam um limite entre $10 \%$ e $20 \%$ de teor em conchas como mais adequado para a fabricação de concreto, entretanto, os mesmos autores apontam que até o limite de $30 \%$ é aceitável, devendo apenas confirmar a segurança através de teste de corpos de prova.

Manikandan e Revathi (2018) apontam que existe uma leve variação da densidade específica dos grãos entre areias marinhas e de rio, o que pode impactar na densidade total do concreto.

Normalmente, areias marinhas são menos graduadas comparadas às areias de rios, sendo que as areias marinhas apresentam um maior percentual de finos (Dhondy et al., 2019).

\subsection{Sais}

A presença de sais solúveis no agregado miúdo é tema de preocupação para a comunidade técnica de engenharia, uma vez que podem acelerar a pega do cimento e com isso inibir a trabalhabilidade do concreto. Podem, também, reagir com o ferro-aluminato tetracálcico $\left(\mathrm{C}_{4} \mathrm{AF}\right)$ e com o aluminato tricálcico $\left(\mathrm{C}_{3} \mathrm{~A}\right)$ para formar cloroaluminatos, o que pode provocar aumento da porosidade e diminuição da resistência do concreto (MORADI, 2021) e (PRANAVAN e SRINIVASAN, 2021)

Outro efeito secundário provocado por íons livres de cloro é a sua ação sobre as armaduras do concreto armado. (CARDOSO, 2009) e (QING et al., 2019).

Estudos conduzidos por Limeira (2010) e Ding (2021) apontam que um baixo risco de corrosão está associado a uma quantidade de cloretos em relação à massa de cimento inferior a 0,4\%, enquanto um risco intermediário está compreendido entre $0,4 \%$ e $1,0 \%$, já os valores superiores ao limite anterior são classificados como de alto risco.

Assim como os cloretos, os sulfatos reagem com diferentes constituintes da pasta (aluminato tricálcico) originando um composto chamado de sal de Candlot. Este é um sal expansivo que, quando formado, pode ocasionar a formação de fissuras e a quebra do concreto (CAVALCANTI; FREIRE, 2007; BAYESTEH, 2020).

O teor de sais da areia é função do teor em água de retenção das areias e da salinidade das águas residuais, dessa forma, por ocasião do escoamento e da secagem da areia, o teor de sais do agregado permanece constante, o que implica na proporcionalidade do teor de sais em função de seu teor em água de retenção (BISHT, 2021).

A norma francesa NF P18-540 (1997) estipula um limite de $0,4 \%$ do teor em enxofre total, (sulfatos e sulfetos), que é medido a partir do teor em $\mathrm{SO}_{3}$.

Nos estudos de Cavalcanti e Freire (2007) e Ferreira (2019), realizados com amostras de areia, considerando o cenário mais desfavorável (uma areia a $21 \%$ de 
água do mar), os níveis de sulfatos presentes nos granulados foram desprezíveis $(0,049 \%)$, mais de oito vezes inferior ao limite aceitável $(0,4 \%)$.

Com relação aos cloretos livres, a NBR 7211 (ABNT, 2009) indica o limite máximo de $0,1 \%$ de íons cloreto em agregado miúdo a ser utilizado no amassamento de concreto armado.

Cavalcanti e Freire (2007) apontam que as normas francesas indicam que, para uma mistura de concreto, o teor em $\mathrm{Cl}^{-1}$ não deve exceder $1 \%$ da massa do cimento para argamassas e concretos não armados, e $0,65 \%$ da massa de cimento para o concreto armado. E no caso de concreto protendido não é permitida a presença de cloretos livres.

Sampath e Mohankumar (2016) apontam que após duas lavagens a concentração de sultetos e cloretos na areia marinha é reduzida a valores satisfatórios a areia marinha tem uma concentração de cloretos de $0,3 \%$ quando saturada, a qual se reduz a $0,075 \%$ após a aplicação do processo de lavagem, sugerindo que a precipitação média seria capaz de levar a areia marinha a níveis aceitáveis para serem usadas em estruturas de concreto armado com aço.

Dhondy et al. (2019) destacam que pesquisas conduzidas em diferentes partes do planeta conduzem a aceitabilidade do uso de areia marinha e água marinha na produção de concreto, e que efeitos adversos como a presença de íons de cloreto podem ser mitigados pelo uso de FRP (fiber reinforced plastic) como armadura. Einde et al. (2003) destacam que o FRP tem a vantagem de maior ciclo de durabilidade e performance superior comparados a armadura de aço.

\subsection{Avaliação ambiental}

As atividades econômicas, de qualquer natureza, não devem se sobrepor à estabilidade do meio físico natural, sobre pena da degradação ambiental e, consequentemente, de efeitos nocivos e irreversíveis ao ecossistema e à vida no Planeta.

Nesta direção, a implantação de um empreendimento de extração de areia está condicionada à diversas legislações ambientais federal, estadual e municipal, seguindo as normativas do órgão competente pelo licenciamento ambiental. No geral, deve-se observar as diretrizes da Agência Nacional de Mineração e do órgão ambiental competente.

Dentro do conceito de instalação de uma estrutura de extração de areia, a delimitação das áreas de influência é fundamental, analisando nesta etapa os possíveis impactos ao meio biótico, físico e socioeconômico.

Gomes et. al. (2000) e Bisht (2021) destacam que a atividade de mineração em fundo marinho pode ocasionar sérios impactos aos ecossistemas marinhos, principalmente devido à destruição de habitats, causada em grande parte pelo aumento da turbidez da água, que interfere na produtividade primária.

É preciso considerar também o processo de transporte da areia extraída até uma área de processamento $\mathrm{e}$ armazenamento, que deverá ser próxima da área de extração. Além disso, este espaço receberá um número grande de visitas de caminhões transportadores que, consequentemente, impactará no tráfego local com aumento de ruídos e riscos de acidentes.

Neste contexto, os impactos adentram o continente e alcançam dimensões que precisam ser bem avaliadas em Estudo de Impacto Ambiental (EIA) e Relatório de Impacto Ambiental (RIMA), que devem ser aprovados pelos órgãos ambientais competentes.

Outro aspecto que não pode ser negligenciado quanto ao uso da areia marinha, refere-se ao seu potencial de radioatividade. Há evidências da existência 
de elementos radioativos na areia marinha que, quando usada na construção de uma casa, pode trazer danos à saúde dos moradores, uma vez que as pessoas experimentam longo período de exposição à radiação emitida pelos elementos que compõem as argamassas e concretos usados na construção (SPERANDIO, 2011).

Durante uma pesquisa realizada nas praias de Camburi, na capital do estado, e Jacaraípe, na Serra, Sperandio (2011), observou-se que o elemento radioativo mais importante presente foi o óxido de tório $\left(\mathrm{ThO}_{2}\right)$, comumente encontrado nas areias monazíticas do litoral brasileiro.

Embora a mensuração da quantidade destes elementos precise de mais aprofundamento investigativo, esta premissa deve ser observada no possível aproveitamento de areias marinhas na construção civil.

No escopo deste trabalho não foi realizado o estudo da radioatividade das areias pesquisadas.
A execução desta pesquisa se processou a partir da análise de três amostras de areias de diferentes fontes: marinha, cava e rio.

\section{MATERIAIS E METODOS}

Os ensaios físicos e mecânicos das amostras foram realizados na empresa Concretest, localizada em Serra-ES. As amostras de areia de cava e rio foram obtidas junto a uma empresa de revenda de areia na Região Metropolitana da Grande Vitória/ES (RMGV).

A areia de rio é originária de lavra em leito de rio no município de Linhares/ES; a areia de cava é proveniente de jazida no município de Aracruz/ES.

A seleção da amostra de areia marinha ocorreu no litoral do município da Serra/ES, em profundidade de $22 \mathrm{~m}$, distante cerca de $2 \mathrm{~km}$ da costa, na altura das coordenadas geográficas latitude $20,130066^{\circ}$ e longitude $-40,153708^{\circ}$, datum WGS84, conforme a Figura 2.

Figura 2: Localização da área de coleta da amostra de areia marinha.

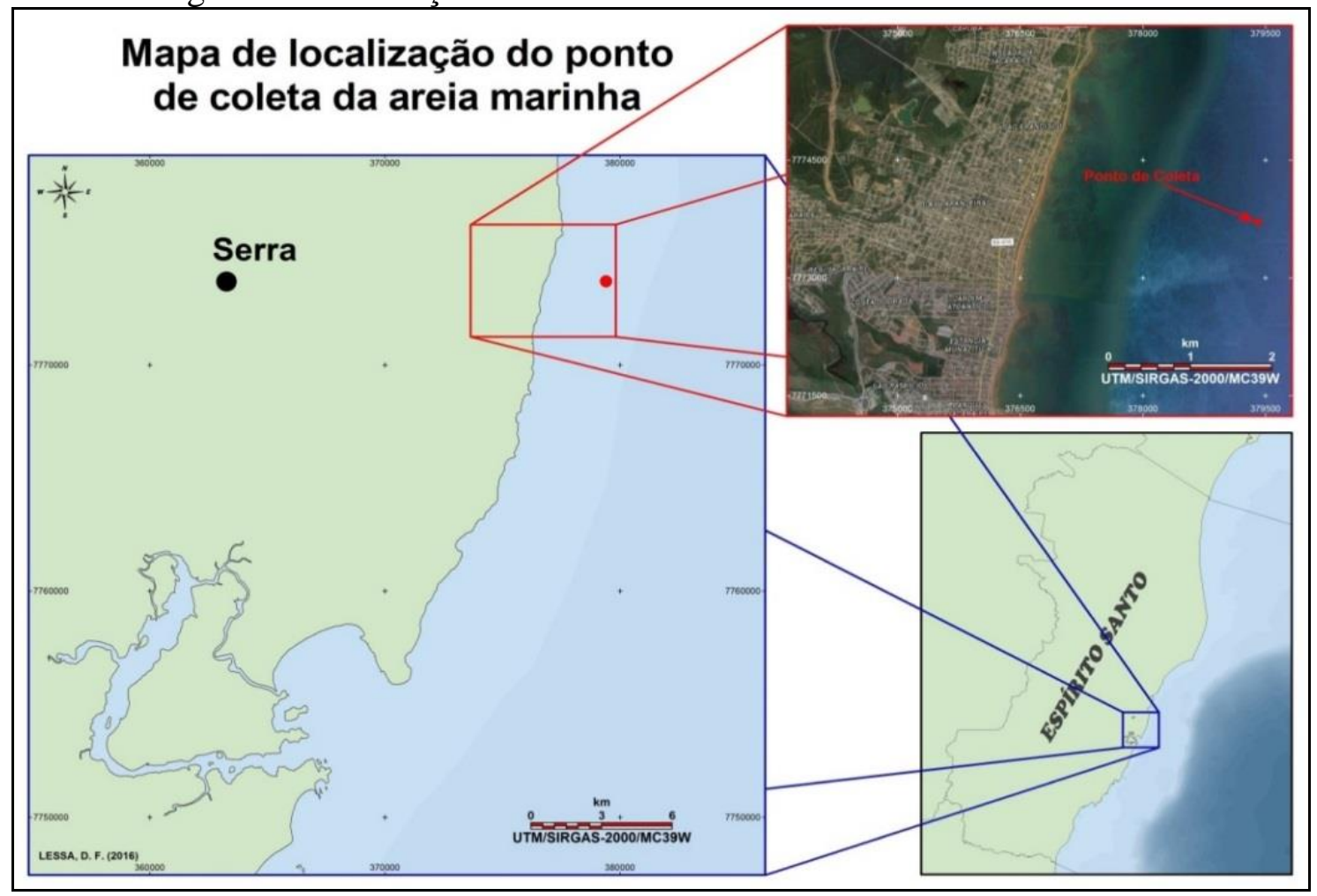

Fonte: Elaborado pelos autores, 2021 
A retirada da amostra de areia foi realizada através da Draga de Ekman (Figura 3), equipamento manual, acoplada a uma corda. O acionamento ocorre a partir do contato com o fundo marinho.

A seleção do local de retirada da amostra ocorreu com base em análise do sistema deposicional marinho raso. Segundo Tianyu (2020), a zona do perfil praial da shoreface (zona de espraiamento) forma a área de domínio de substrato de areia. A profundidade e o comprimento da shoreface é dependente do domínio das ondas. A posição também foi função da facilidade de acesso, por se localizar próxima ao cais de barcos de pesca de
Jacaraípe, ponto de partida da embarcação. A Figura 4 apresenta um esquema típico de praia.

Em todas as amostras de areia foram realizados os seguintes ensaios para a caracterização dos agregados: composição granulométrica, massa específica, teor de argilas em torrões e materiais friáveis, teor de materiais pulverulentos, dimensão máxima característica $\left(D_{\text {máx }}\right)$ avaliação de impurezas orgânicas solúveis, teor de cloretos solúveis, teor de sais solúveis, teor de sulfatos solúveis, teor de materiais carbonosos e pH (potencial de hidrogênio).

Figura 3: Draga de Ekman

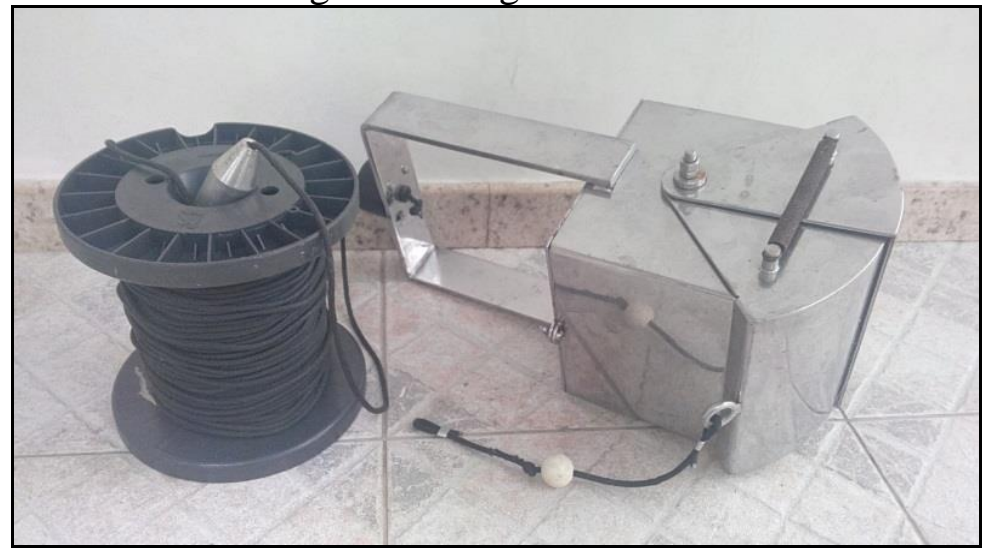

Fonte: Elaborado pelos autores, 2016.

Figura 3: Esquema de perfil de praia.

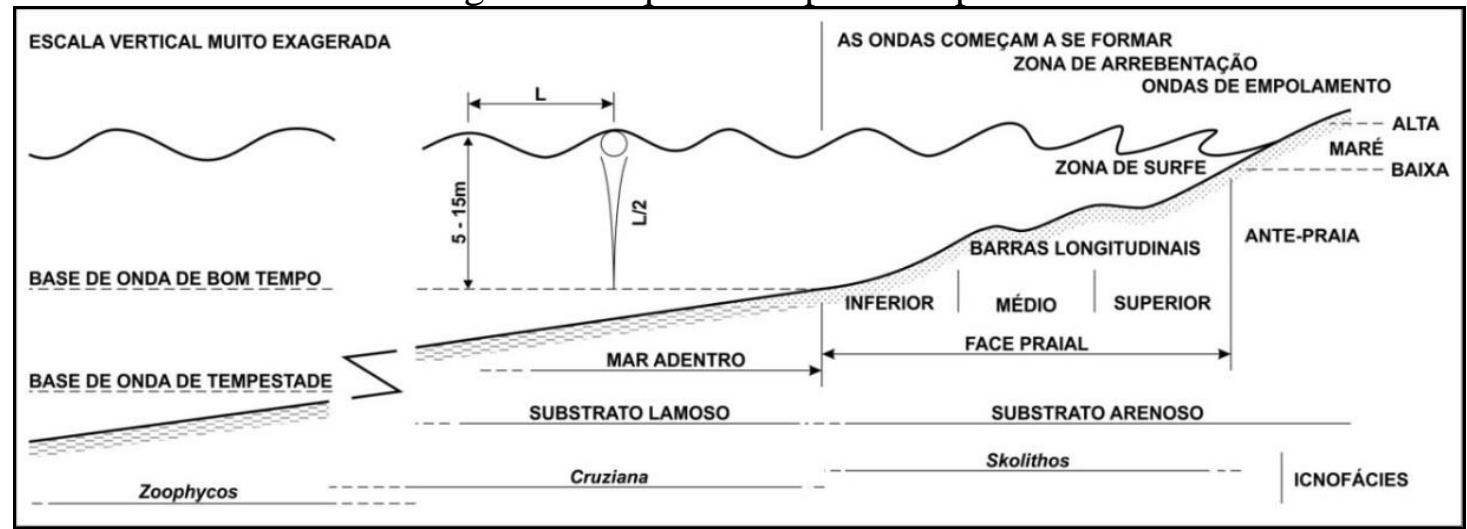

Fonte: Elaborado pelos autores, 2021 
Após as análises física e química dos agregados miúdos, esses foram utilizados para a preparação de concretos e posteriormente moldados 7 corpos de prova cilíndricos $(10 \mathrm{~cm}$ de diâmetro com $20 \mathrm{~cm}$ de altura) de cada tipo de agregado, para o rompimento em 7, 28 e 90 dias (média de 2 corpos de prova para cada rompimento).

Após 90 dias, um corpo de prova de cada areia foi imerso em água do mar durante 7 dias e, após este prazo, a amostra foi seccionada em 2 partes iguais, sendo duas utilizadas para o teste de carbonatação e duas para a avaliação de penetração de cloretos.

$O$ teste de carbonatação foi realizado através da aspersão da solução de fenolftaleína $\left(\mathrm{C}_{20} \mathrm{H}_{16} \mathrm{O}_{4}\right)$ a $1 \%$ nas duas partes do corpo de prova seccionado no sentido longitudinal.

A coloração magenta representa ambiente básico, ou seja, essa região do do concreto está protegida da presença de $\mathrm{CO}_{2}$ da atmosfera (que não sofreu carbonatação), substância responsável pela carbonatação

A avaliação da penetração de cloretos no corpo de prova seguiu a norma europeia UNI 1603925 (2019). Após 7 dias imersos em água do mar, o corpo de prova foi seccionado no sentido longitudinal e, em seguida, foi aspergida a solução de nitrato de prata $\left(\mathrm{AgNO}_{3}\right)$ 0,1M.

Como resultado da reação da solução com os íons de cloro, forma-se um precipitado branco de cloreto de prata na superfície do concreto; onde não há cloretos livres a cor fica marrom. Importante frisar que a solução de nitrato de prata é cáustica e irritante à pele, sendo indispensável o uso de luvas e máscaras para a sua manipulação.

As amostras de areia foram previamente lavadas e posteriormente foram moldados corpos de prova conforme a NBR 5738 (2016) no formato cilíndrico de $100 \mathrm{~mm}$ x $200 \mathrm{~mm}$, preenchidos com concreto em duas camadas sucessivas, cada uma delas recebendo 12 golpes com a haste de adensamento. Optou-se por utilizar como referência um abatimento (slump) de $10 \mathrm{~cm}+/-2 \mathrm{~cm}$ para todas as areias. O slump de $10 \mathrm{~cm}+/-2 \mathrm{~cm}$ foi utilizado como parâmetro para definir a relação água cimento média ideal.

Para a confecção dos corpos de prova foi utilizado o cimento CP-IV-32RS, cimento portland com adição de pozolana, que apresenta a característica adicional de resistência a sulfatos.

Os corpos de provas após a desmoldagem foram retificados e, a seguir, foram realizados os ensaios de compressão axial para verificar a resistência do concreto nas idades de 7, 28 e 90 dias. $\mathrm{O}$ cálculo da resistência a compressão foi realizado conforme equação (seção 6.1) da norma NBR 5739 (2019). A Tabela 3 apresenta a dosagem dos concretos enquanto a Tabela 4 apresenta o resumo dos ensaios e suas respectivas normas técnicas de referência utilizadas

Tabela 3: Dosagem do concreto de moldagem dos corpos de prova.

\begin{tabular}{cccccccc}
\hline Agregado miúdo & $\begin{array}{c}\text { Cimento } \\
(\mathbf{k g})\end{array}$ & $\begin{array}{c}\text { Areia } \\
(\mathbf{k g})\end{array}$ & $\begin{array}{c}\text { Brita 0 } \\
(\mathbf{k g})\end{array}$ & $\begin{array}{c}\text { Brita 1 } \\
(\mathbf{k g})\end{array}$ & $\begin{array}{c}\text { Água } \\
\text { Umidade } \\
(\mathbf{m l})\end{array}$ & $\begin{array}{c}\text { Água } \\
(\mathbf{m l})\end{array}$ & $\begin{array}{c}\text { Relação } \\
\text { água/cimento }\end{array}$ \\
\hline Areia Marinha & 7 & 14,2 & 7,0 & 7,0 & 380 & 4220 & 0,657 \\
Areia de Cava & 7 & 14,2 & 7,0 & 7,0 & 932 & 3668 & 0,657 \\
Areia de Rio & 7 & 14,2 & 7,0 & 7,0 & 100 & 4500 & 0,657 \\
\hline
\end{tabular}


Tabela 4: Resumo dos ensaios realizados

\begin{tabular}{ll}
\hline \multicolumn{1}{c}{ Norma Técnica } & \multicolumn{1}{c}{ Ensaio realizado } \\
\hline ASTM C123:2014 & Teor de materiais carbonosos \\
\hline NBR 5738: 2015 & Moldagem e cura de corpos de prova \\
\hline NBR 5739: 2019 & Ensaio de compressão de corpos de prova cilíndricos \\
\hline NBR 7211:2009 & Agregados para concretos - especificações \\
\hline NBR 7218:2010 & Teor de argila em torrões e materiais friáveis \\
\hline NBR 7221: 2012 & Avaliação de impurezas orgânicas \\
\hline NBR 7353: 2019 & Determinação do pH com eletrodos de vidro \\
\hline NBR 9774:1987 & Verificação da reatividade potencial pelo método químico \\
\hline NBR 9917:2009 & Determinação de sais, cloretos e sulfatos solúveis \\
\hline NBR NM 248:2003 & Dimensão máxima característica e módulo de finura \\
\hline NBR NM 46:2001 & Teor de materiais pulverulentos \\
\hline NBR NM 49:2001 & Determinação de impurezas orgânicas \\
\hline NBR NM 53 & Massa específica \\
UNI 1603925 & Penetração de íons cloretos \\
\hline
\end{tabular}

\section{RESULTADOS E DISCUSSÕES}

Da caracterização granulométrica das areias, constatou-se que as três amostras (Figura 5) se enquadram como areia média, com módulo de finura compreendido dentro do intervalo de 2,4 a 3,3 .

A areia marinha apresentou maior concentração de grãos retidos nas peneiras $1,18 \mathrm{~mm}$ e $0,3 \mathrm{~mm}(52,81 \%$ e $29,52 \%$, respectivamente). Já a areia lavada (de rio) apresentou maior concentração nas peneiras $0,6 \mathrm{~mm}$ e $0,3 \mathrm{~mm}(44,44 \%$ e $28,98 \%$, respectivamente).

E, por fim, a areia de cava concentrou $35,95 \%$ dos grãos na peneira de abertura $1,18 \mathrm{~mm}$ e $34,66 \%$ na peneira 0,6 $\mathrm{mm}$. A Figura 6 apresenta as curvas granulométricas das amostras de agregado miúdo investigadas.

Figura 4: Curva granulométrica das areias.

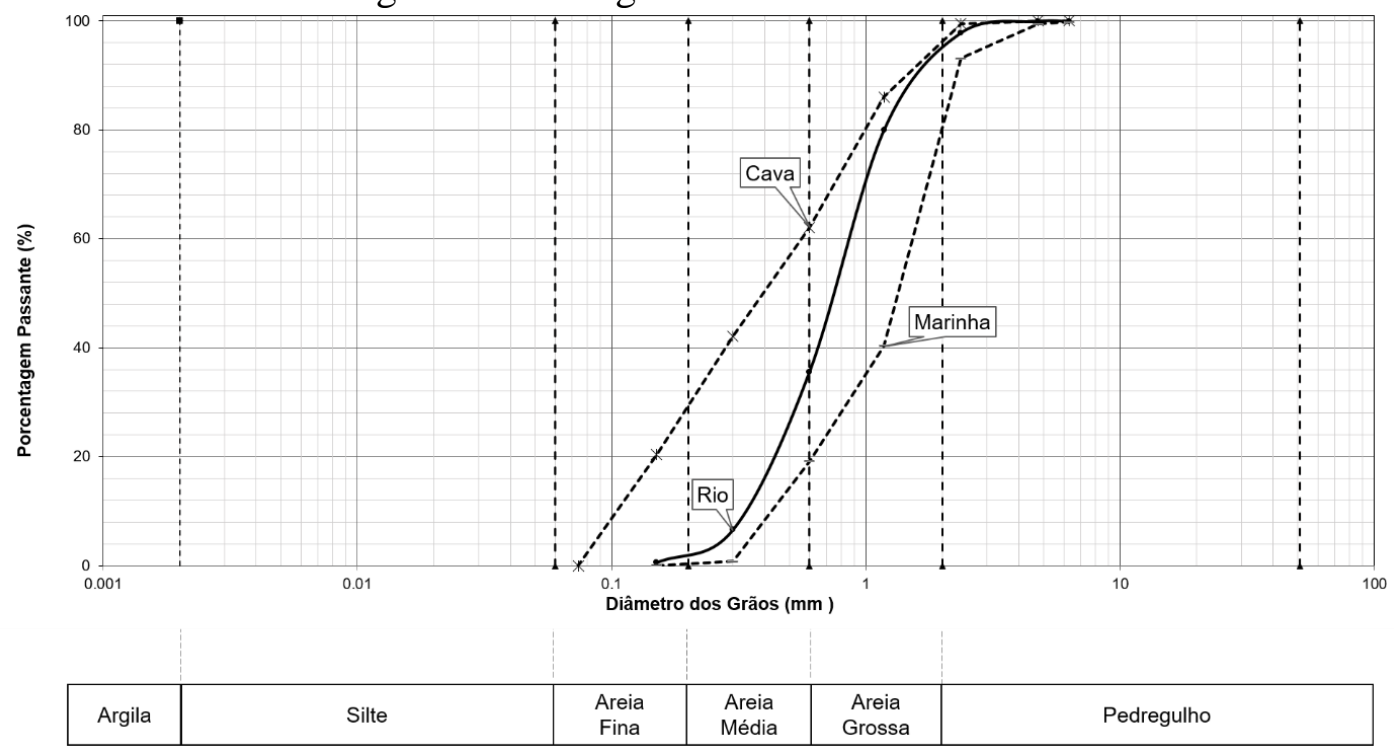


Figura 5: Amostras de areias utilizadas na pesquisa

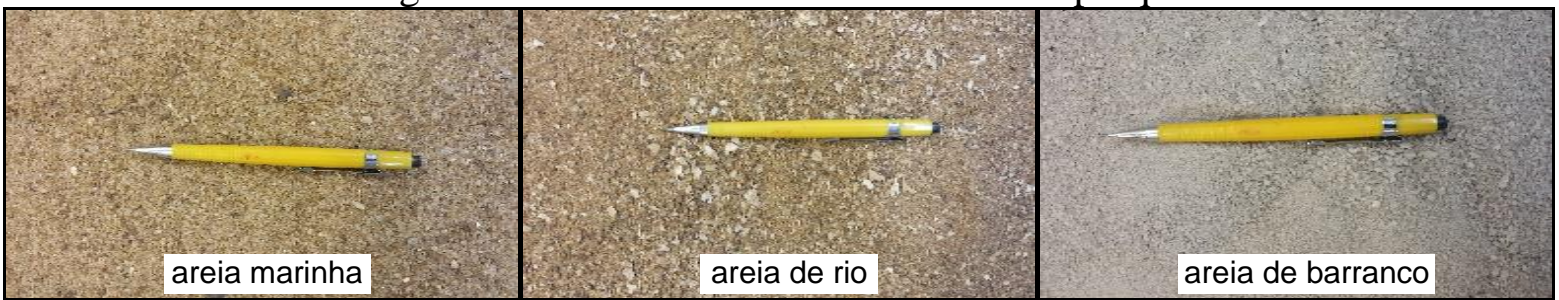

Fonte: Elaborado pelos autores, 2021

Com relação aos demais testes realizados, a areia marinha apresentou resultados aderentes as normas técnicas de avaliação das características dos agregados miúdos, com exceção do teor de materiais carbonosos, 2,93\%, valor acima do limite estabelecido pela norma ASTM C123 (2014), de 1,00\%.

Entretanto, este valor pode estar associado à localização geográfica da retirada das amostras no mar, que está situada entre dois rios que desaguam na praia de Jacaraípe/ES, Brasil.

Uma resposta a este problema poderia ser fruto de uma experiência com amostra de areia marinha retirada, preferencialmente mais ao norte dos cursos da desembocadura dos rios para se evitar a influência da deposição de matéria orgânica e o controle do retrabalhamento deste material pelas correntes marítimas.
A Tabela 5 apresenta os resultados dos ensaios químicos e físicos das amostras de areia.

Para a avaliação da resistência dos corpos de prova à compressão foram rompidas duas amostras nas idades de 7 , 28 e 90 dias, resultando em valores satisfatórios para o concreto confeccionado com agregado marinho.

$\mathrm{Na}$ idade de 28 dias, o concreto com areia marinha apresentou resistência à compressão de 32,19 $\mathrm{MPa}$, contra 34,10 $\mathrm{MPa}$ do concreto com areia lavada de rio e 35,09 MPa do concreto com areia de cava.

Essa relação também se manteve para as idades de 28 e 90 dias, mostrando uma aproximação do valor da resistência entre os concretos moldados com areia marinha e de rio. A Tabela 6 apresenta os resultados em todas as idades testadas.

Tabela 5: Comparação das características do agregado marinho e continental.

\begin{tabular}{lcccc}
\hline & $\begin{array}{c}\text { Areia } \\
\text { Marinha }\end{array}$ & $\begin{array}{c}\text { Areia de } \\
\text { Rio }\end{array}$ & $\begin{array}{c}\text { Areia de } \\
\text { Cava }\end{array}$ & Padrão \\
\hline Dimensão máxima característica (Dmáx) & $4,75 \mathrm{~mm}$ & $4,75 \mathrm{~mm}$ & $2,36 \mathrm{~mm}$ & - \\
(NBR NM 248:2003) & 2,66 & 2,80 & 3,02 & - \\
Módulo de finura (NBR NM 248:2003) & $0,49 \%$ & $0,12 \%$ & $0,20 \%$ & $\leq 1,50 \%$ \\
\hline Teor de argila e materiais friáveis (NBR 7218) & $2,597 \mathrm{~g} / \mathrm{cm}^{3}$ & $2,648 \mathrm{~g} / \mathrm{cm}^{3}$ & $2,625 \mathrm{~g} / \mathrm{cm}^{3}$ & - \\
Massa específica (NBR NM 53:2009) & $<0,03 \%$ & $<0,03 \%$ & $<0,03 \%$ & $\leq 0,03$ \\
Avaliação de impurezas orgânicas (NBR 7221:2012) & $0,326 \%$ & $0,680 \%$ & $0,812 \%$ & $3,000 \%$ \\
Teor de materiais pulverulentos (NBR NM 46:2003) & $0,0917 \%$ & $0,0005 \%$ & $0,0018 \%$ & 0,1000 \\
Teor de cloretos solúveis (NBR 9917:2009) & $0,0130 \%$ & $0,0010 \%$ & $0,0030 \%$ & $\leq 0,1000$ \\
Teor de sulfatos solúveis (NBR 9917:2009) & $0,2053 \%$ & $0,0073 \%$ & $0,0120 \%$ & 0,3000 \\
Teor de sais solúveis (NBR 9917:2009) & $2,93 \%$ & $0,31 \%$ & $0,08 \%$ & 1,00 \\
Teor de materiais carbonosos (ASTM C123:2014) & 6,86 & 7,62 & 7,57 & $5,50 / 9,00$ \\
\hline pH - Potencial de hidrogênio (NBR 7353:2019) & & & & \\
\hline
\end{tabular}


Tabela 6: Resistência dos corpos de prova à compressão (cimento CP-IV-32RS)

\begin{tabular}{cccc}
\hline $\begin{array}{c}\text { Idade do concreto } \\
\text { (dias) }\end{array}$ & $\begin{array}{c}\text { Areia marinha } \\
\text { (Mpa) }\end{array}$ & $\begin{array}{c}\text { Areia de rio } \\
\text { (Mpa) }\end{array}$ & $\begin{array}{c}\text { Areia de cava } \\
\text { (Mpa) }\end{array}$ \\
\hline $\mathbf{7}$ & $18,46 \pm 1,32$ & $17,42 \pm 0,87$ & $18,78 \pm 1,21$ \\
$\mathbf{2 8}$ & $32,19 \pm 1,63$ & $34,10 \pm 0,32$ & $32,94 \pm 0,61$ \\
$\mathbf{9 0}$ & $33,83 \pm 2,01$ & $35,41 \pm 1,87$ & $35,09 \pm 0,17$ \\
\hline
\end{tabular}

O ensaio de carbonatação revelou que as três amostras não sofreram processo de redução de $\mathrm{pH}$. O ensaio revelou que a profundidade da carbonatação na amostra foi incipiente.

A coloração magenta revela a área com pH básico, adequada à proteção das armaduras. Já a porção do corpo de prova que não sofreu alteração da cor representa um ambiente mais ácido. A Figura 7 apresenta uma visão dos corpos de prova ensaiados investigados.

$\mathrm{Na}$ mesma direção, o ensaio com aspersão de nitrato de prata mostra que as profundidades da presença de cloretos livres nas amostras de todos os agregados foram imperceptíveis.

Com a reação do nitrato de prata com os íons de cloreto livres no concreto, espera-se a ocorrência de um precipitado de coloração branca, caso a coloração seja marrom, isso indica que os cloretos presentes nos corpos de prova estão na forma combinada.

Na Figura 8 não é possível notar a presença cloretos livres nas amostras analisadas, com destaque para a areia de rio que apresentou a menor quantidade de cloretos, mesmo na forma combinada.

Figura 6: Avaliação de cloretos livres nas amostras através do teste de nitrato de prata.
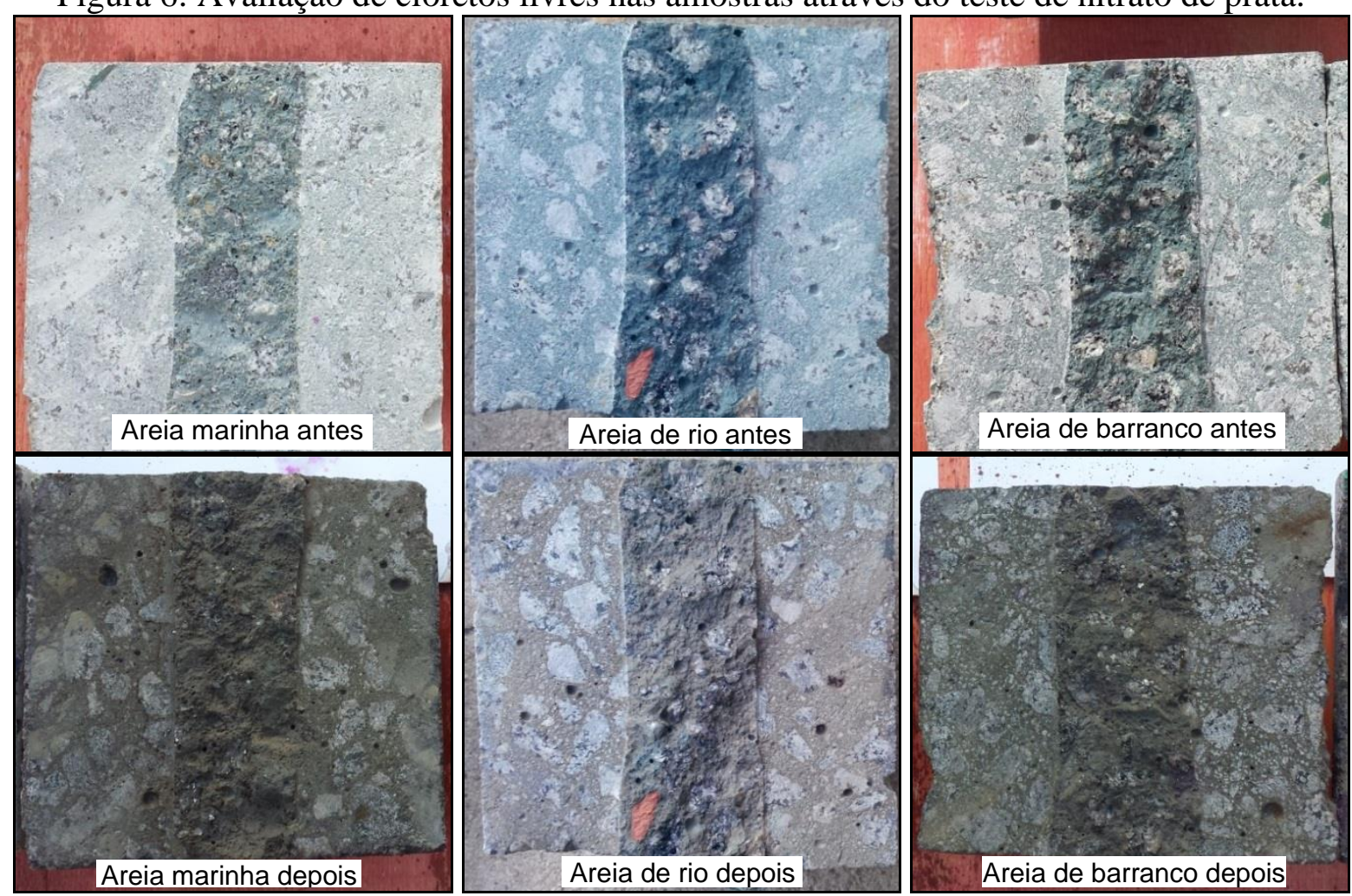
Figura 7: Medidas das profundidades de carbonatação nos corpos de prova.
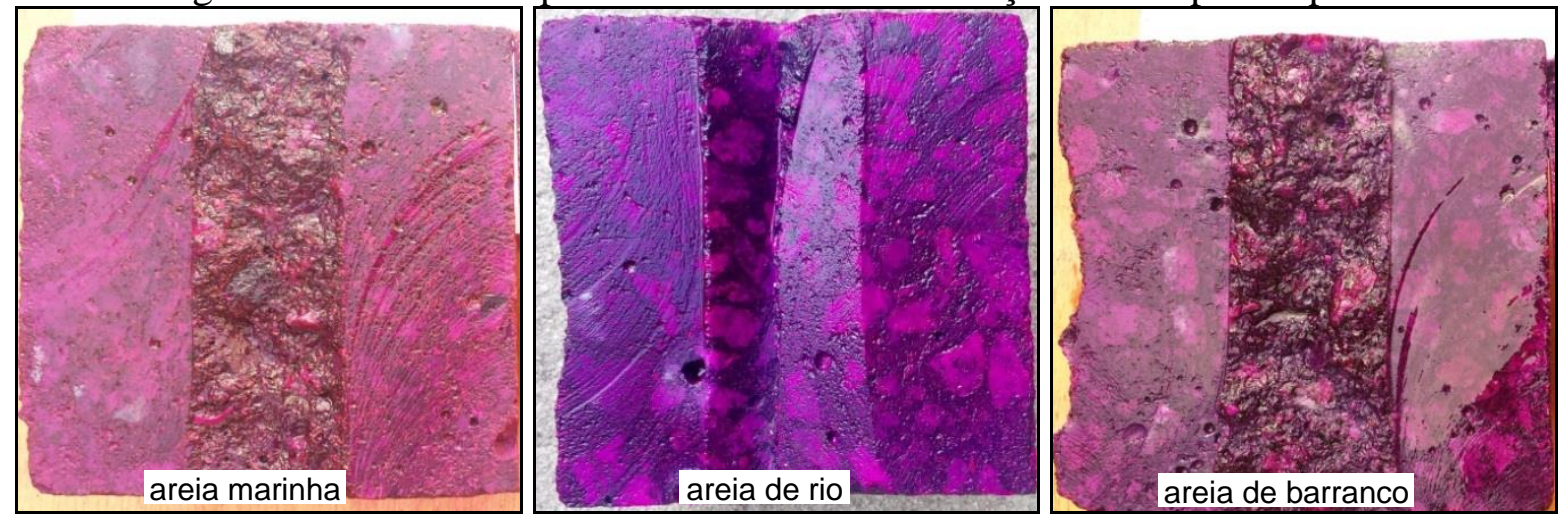

\section{CONCLUSÃO}

Evidentemente esta pesquisa não tem a pretensão de esgotar o estudo sobre a utilização da areia marinha como agregado miúdo, mas sim, contribuir para a discussão sobre novos paradigmas que afetam as fronteiras da construção civil acerca de novas tecnologias.

Diante deste quadro, a possível utilidade de areia marinha se apresenta como importante recurso. Diante da discussão de estudos realizados por diversos pesquisadores, tanto no Brasil quanto em outros países e da presente pesquisa, nota-se a viabilidade do emprego de areias siliciclásticas marinhas na fabricação de concreto, desde que se considere a sua retirada em local afastado da foz de rios para reduzir a presença de materiais carbonosos. Aspectos mais sensíveis, como a presença de sais e bioclastos, mostraram-se dentro dos limites estabelecidos pelas normas técnicas.

Para a região de estudo, litoral de Jacaraípe/ES, Brasil, a amostra de areia marinha apresentou índice inicial de $25 \%$ de bioclastos, entretanto, após passar na peneira de $4,00 \mathrm{~mm}$, a presença destes elementos se reduziu a 19\%, limite considerado adequado.

Do ponto de vista granulométrico, a areia estudada apresentou $D_{\text {máx }}$ de 4,75 $\mathrm{mm}$, e módulo de finura de 2,66, valores considerados apropriados para a utilização na fabricação de concreto. $\mathrm{O}$ agregado marinho apresentou um valor de apenas $0,013 \%$ de sulfatos solúveis, inferior a $2 \%$ estabelecido pela NBR 9917 (2009).

$\mathrm{Na}$ mesma direção, o teor de cloretos solúveis $(0,0917 \%)$ e de sais solúveis $(0,2053 \%)$ mantiveram-se dentro dos valores limites estabelecidos em norma.

Os ensaios de avaliação da profundidade de carbonatação e da presença de cloretos nos corpos de prova mostraram que nos concretos moldados com areia de mar e cava foi maior a presença de cloretos na forma combinada, revelados pela coloração marrom escurecida.

Por outro lado, o concreto com areia de rio foi o que apresentou a menor quantidade de cloretos, tanto livres quanto combinados, conforme observado em sua coloração mais clara, e também sem a presença de precipitados de cloretos de prata.

Essas constatações são corroboradas pelos testes químicos realizados nas amostras dos agregados, onde a areia de rio apresentou os menores índices de presença de cloretos solúveis $(0,00005 \%)$, contra $0,0917 \%$ da de mar e $0,0018 \%$ da de cava, além disso, a areia de rio também tem os menores índices de sais $(0,0073 \%)$ e sulfatos $(0,0010 \%)$ solúveis.

A discussão apresentada nesta pesquisa merece ser estendida para 
abranger a avaliação de mais amostras marinhas no litoral do estado, delimitandose, assim, as áreas com melhores qualidades dos agregados.

Espera-se também que, em pesquisas subsequentes, seja avaliada a penetração de íons de cloretos livres em corpos moldados com maior intervalo de tempo.

\section{REFERÊNCIAS}

ASTM C123 / C123M-14. Standard Test Method for Lightweight Particles in Aggregate, American Society for Testing and Materials, 2014

AUGRIS, Claude; CRESSARD, Alain $P$. Les granulats marins, Paris, Rapport Scientifique et Technique, n. 51, 90 p. 1984

BAYESTEH, Hamed; SHARIFI, Mahdi; HAGHSHENAS, Ali. Effect of stone powder on the rheological and mechanical performance of cement-stabilized marine clay/sand. Construction and Building Materials, v. 262, p. 120792. 2020, http://dx.doi.org/10.1016/j.conbuildmat.20 20.120792

BISHT, Arpita. Conceptualizing sand extractivism: deconstructing an emerging resource frontier. The Extractive

Industries and Society, v. 8, n. 2, p. 100904. 2021, http://dx.doi.org/10.1016/j.exis.2021.1009 04

CARDOSO, Wandercleiton. Efeitos do nióbio na microestrutura e resistência à corrosão do aço inoxidável austenoferrítico SEW 410 nr. 1.4517. 2009. 63 f. Dissertação (Mestrado em Engenharia Metalúrgica e de Materiais), Instituto Federal do Espirito Santo, Vitória-ES, 2009, https://doi.org/10.29327/4227903
CAVALCANTI, Vanessa; FREIRE, Georg e. A Possibilidade de Utilização de Areias Marinhas como Agregado na Construção Civil na Região Metropolitana de Fortaleza. Gravel, Porto Alegre, v. 5, p. 11-24, 2007

DHONDY, Tanaz; REMENNIKOV, Alex; SHIEKH, M. Neaz. Benefits of using sea sand and seawater in concrete: a comprehensive review. Australian Journal of Structural Engineering, v. 20, n. 4, p. 280-289, 2019, http://dx.doi.org/10.1080/13287982.2019.1 659213

DING, Zhi; HE, Shao-Heng; SUN, Yifei; XIA, Tang-Dai; ZHANG, Qiong-Fang. Comparative study on cyclic behavior of marine calcareous sand and terrigenous siliceous sand for transportation infrastructure applications. Construction and Building Materials, v. 283, 2021, http://dx.doi.org/10.1016/j.conbuildmat.20 21.122740

EINDE, Lelli van Den; ZHAO, Lei; SEIBLE, Frieder. Use of FRP composites in civil structural applications. Construction and Building Materials, v. 17 , n. 6-7, p. 389-403, 2003, http://dx.doi.org/10.1016/s09500618(03)00040-0

FERREIRA, Ruan L. S; COSTA, Túlio C. S.; Sá, Maria, das Vitórias Vieira; Carneiro, Arnaldo M. Pereira. Efeitos do uso de areia de praia nas propriedades de argamassas mistas: análise da variação granulométrica. Revista Matéria, Rio de Janeiro, v. 24, n. 2, 2019, https://doi.org/10.1590/s1517707620190002.0681

GOMES, Abílio S.; PALMA, Jorge J. C.; SILVA, Cleverson G. Causas e consequências do impacto ambiental da exploração dos recursos minerais marinhos. Revista Brasileira de

Geofísica, v. 18, n. 3, p. 447-454, 2000, 
HUANG, Bo-Tao et al. Seawater sea-sand engineered/strain-hardening cementitious composites (ECC/SHCC): Assessment and modeling of crack characteristics. Cement and Concrete Research, v. 140, 2021.

https://doi.org/10.1016/j.cem conres.2020.106292

HUANG, Bo-Tao; YU, Jing; WU, Jia-Qi; DAI, Jian-Guo; LEUNG, Christopher Ky. Seawater sea-sand Engineered Cementitious Composites (SS-ECC) for marine and coastal applications. Composites Communications, v. 20, p. 100353, 2020, http://dx.doi.org/10.1016/j.coco.2020.04.0 19

LIMEIRA, J.; AGULLO, L.; ETXEBERRIA, M. Dredged marine sand in concrete: an experimental section of a harbor pavement. Construction and Building Materials, v. 24, n. 6, p. 863870, 2010, http://dx.doi.org/10.1016/j.conbuildmat.20 09.12.011

MANIKANDAN, R; REVATHI, S. Behavioural Study on Treated Sea Sand as a Fine Aggregate in Concrete. Journal of Advances in Civil Engineering, v. 4, n. 2, p. 8-14, 2018.

http://dx.doi.org/10.18831/djcivil.org/2018 021002

MORADI, Saeed; SHAHNOORI, Shore. Eco-friendly mix for Roller-Compacted Concrete: effects of Persian-gulf-dredged marine sand on durability and resistance parameters of concrete. Construction and Building Materials, v. 281. 2021. http://dx.doi.org/10.1016/j.conbuildmat.20 21.122555

NBR 5738. Concreto - Procedimento para moldagem e cura de corpos de prova. Associação Brasileira de Normas Técnicas, Rio de Janeiro,2015
NBR 5739. Concreto - Ensaio de compressão de corpos de prova cilíndricos. Associação Brasileira de Normas Técnicas, Rio de Janeiro, 2019

NBR 7211. Agregados para concretos especificações. Associação Brasileira de Normas Técnicas, Rio de Janeiro, 2009

NBR 7218. Determinação do teor de argila em torrões e materiais friáveis. Associação Brasileira de Normas Técnicas, Rio de Janeiro, 2010

NBR 7220. Avaliação das impurezas orgânicas das areias para concreto. Associação Brasileira de Normas Técnicas, Rio de Janeiro, 1992

NBR 7221. Índice de agregado miúdo contendo impurezas orgânicas - método de ensaio. Associação Brasileira de Normas Técnicas, Rio de Janeiro, 2012

NBR 7353. Soluções aquosas Determinação do pH com eletrodos de vidro. Associação Brasileira de Normas Técnicas, Rio de Janeiro, 2019

NBR 9774. Verificação da reatividade potencial pelo método químico - Método de ensaio. Associação Brasileira de Normas Técnicas, Rio de Janeiro, 1987

NBR 9917. Agregados para concretoDeterminação de sais, cloretos e sulfatos solúveis. Associação Brasileira de Normas Técnicas, Rio de Janeiro, 2009

NBR NM 248. Agregados Determinação da composição granulométrica. Associação Brasileira de Normas Técnicas, Rio de Janeiro, 2003

NBR NM 46. Agregados - Determinação do material fino que passa através da peneira $75 \mu \mathrm{m}$, por lavagem Associação Brasileira de Normas Técnicas, Rio de Janeiro, 2001 
NBR NM 53. Agregado graúdo Determinação de massa específica, massa específica aparente e absorção de água. Associação Brasileira de Normas Técnicas, Rio de Janeiro, 2009

NF P18-540. Granulats - Granulats naturels pour bétons hydrauliques. Association Française de Normalisation, Paris, 1997

QING Xu, Tao Ji, Zhengxian Yang, Yilong Ye, Preliminary investigation of artificial reef concrete with sulphoaluminate cement, marine sand and sea water,

Construction and Building Materials, Volume 211, 2019, Pages 837-846, https://doi.org/10.1016/j.conbuildmat.2019 .03 .272

QING Xu, Tao Ji, Zhengxian Yang, Yilong Ye, Steel rebar corrosion in artificial reef concrete with sulphoaluminate cement, sea water and marine sand, Construction and Building Materials, Volume 227, 2019, https://doi.org/10.1016/j.conbuildmat.2019 .116685

PRANAVAN, S.; G. SRINIVASAN, Investigation on behaviour of M-sand and sea sand-based concrete, Materials Today: Proceedings, Volume 45, Part 7 , 2021, Pages 7079-7085, https://doi.org/10.1016/j.matpr.2021.01.93 0

SAMPATH, B., and G. MOHANKUMAR. Preliminary Study on the Development of Concete with Sea Sand as Fine Aggregate. Indian Journal of Science and Technology, v. 9, n. 32, p. 1-5. 2016, http://dx.doi.org/10.17485/ijst/2016/v9i32/ 98631

SILVA, Gabriel; VIEIRA, Rogério; OLIVEIRA, Douglas. Viabilidade do uso de areia de praia aplicada em argamassas de revestimento. Revista Perquirere, v. 15, n. 3 , p. $40-54,2018$
SPERANDIO, Etory. Radioatividade natural e composição das areias da praia de Camburi em Vitória, ES. 2011. $121 \mathrm{f}$. Dissertação (Mestrado), Centro de Ciências Exatas, Universidade Federal do Espírito Santo. Vitória/ES, Brasil, 2011

TAMAR TROP, An overview of the management policy for marine sand mining in Israeli Mediterranean shallow waters, Ocean \& Coastal Management, Volume 146, 2017, Pages 77-88, https://doi.org/10.1016/j.ocecoaman.2017. 06.013

TIANYU Li, Xiaoyan Liu, Yumei Zhang, Heng Yang, Zihan Zhi, Li Liu, Wenli Ma, Surendra P. Shah, Weihua Li, Preparation of sea water sea sand high performance concrete (SHPC) and serving performance study in marine environment,

Construction and Building Materials, Volume 254, 2020, https://doi.org/10.1016/j.conbuildmat.2020 .119114

TING, Matthew Zhi Yeon; WONG, Kwong Soon; RAHMAN, Muhammad Ekhlasur; JOO, Meheron Selowara. Mechanical and durability performance of marine sand and seawater concrete incorporating silicomanganese slag as coarse aggregate. Construction and Building Materials, v. 254. 2020. http://dx.doi.org/10.1016/j.conbuildmat.20 20.119195

UNI 1603925. Prove sul calcestruzzo indurito - Determinazione della profondità di penetrazione degli ioni cloruro, Italian Standard, Roma, 2019

XIAO, Jianzhuang; QIANG, Chengbing; NANNI, Antonio; ZHANG, Kaijian. Use of sea-sand and seawater in concrete construction: current status and future opportunities. Construction and Building Materials, v. 155, p. 1101-1111. 2017 http://dx.doi.org/10.1016/j.conbuildmat.20 17.08.130 
XU He, Jikai Zhou, Mechanical characteristics of sea-sand concrete in simulated marine environment, Construction and Building Materials, Volume 274, 2021, https://doi.org/10.1016/j.conbuildmat.2020 .122098

YAMASHITA, E.; Arlyn Aristo CIKMIT, Takashi Tsuchida, Ryota Hashimoto, Strength estimation of cement-treated marine clay with wide ranges of sand and initial water contents, Soils and

Foundations, Volume 60, Issue 5, 2020, Pages 1065-1083, https://doi.org/10.1016/j.sandf.2020.05.002

ZHANG, Q.; Ping Wang, Wenjie Wang, Yixiang Zhang, Marine sand resources in the Pearl River estuary waters of China, Journal of Marine Systems, Volume 82, Supplement, 2010, Pages S83-S89, https://doi.org/10.1016/j.jmarsys.2010.02.007

ZHANG, Qiaomin et al. Marine sand resources in the Pearl River estuary waters of China. Journal of Marine Systems, v. 82, p. 83-89, 2010, https://doi.org/10.1016/j.jmarsys.2010.02.0 07

ZHOU, J.; Xu He, Lunchao Zhang, CT characteristic analysis of sea-sand concrete exposed in simulated marine environment, Construction and Building Materials, Volume 268, 2021, https://doi.org/10.1016/j.conbuildmat.2020.121 170 